\title{
GMR
}

\section{Genetic diversity and population structure analysis in Perilla frutescens from Northern areas of China based on simple sequence repeats}

\author{
S.J. Ma, K.J. Sa, T.K. Hong and J.K. Lee \\ Department of Applied Plant Sciences, College of Agriculture and Life Sciences, \\ Kangwon National University, Chuncheon, Korea \\ Corresponding author: J.K. Lee \\ E-mail: jukyonglee@kangwon.ac.kr \\ Genet. Mol. Res. 16 (3): gmr16039746 \\ Received June 8, 2017 \\ Accepted August 11, 2017 \\ Published September 21, 2017 \\ DOI http://dx.doi.org/10.4238/gmr16039746
}

Copyright (C) 2017 The Authors. This is an open-access article distributed under the terms of the Creative Commons Attribution ShareAlike (CC BY-SA) 4.0 License.

\begin{abstract}
In this study, 21 simple sequence repeat (SSR) markers were used to evaluate the genetic diversity and population structure among 77 Perilla accessions from high-latitude and middle-latitude areas of China. Ninety-five alleles were identified with an average of 4.52 alleles per locus. The average polymorphic information content (PIC) and genetic diversity values were 0.346 and 0.372 , respectively. The level of genetic diversity and PIC value for cultivated accessions of Perilla frutescens var. frutescens from middle-latitude areas were higher than accessions from high-latitude areas. Based on the dendrogram of unweighted pair group method with arithmetic mean (UPGMA), all accessions were classified into four major groups with a genetic similarity of $46 \%$. All accessions of the cultivated var. frutescens were discriminated from the cultivated $P$. frutescens var. crispa. Furthermore, most accessions of the cultivated var. frutescens collected in highlatitude and middle-latitude areas were distinguished depending on their geographical location. However, the geographical locations of several accessions of the cultivated var. frutescens have no relation with
\end{abstract}

Genetics and Molecular Research 16 (3): gmr16039746 
their positions in the UPGMA dendrogram and population structure. This result implies that the diffusion of accessions of the cultivated Perilla crop in the northern areas of China might be through multiple routes. On the population structure analysis, 77 Perilla accessions were divided into Group I, Group II, and an admixed group based on a membership probability threshold of 0.8 . Finally, the findings in this study can provide useful theoretical knowledge for further study on the population structure and genetic diversity of Perilla and benefit for Perilla crop breeding and germplasm conservation.

Key words: Perilla frutescens; Genetic similarity; SSR marker; UPGMA; Geographical location; Polymorphic information content

\section{INTRODUCTION}

Perilla frutescens (L.) Britt. is a self-fertilizing crop in the family of mint, Lamiaceae. Depending on their morphological characteristics and availability, this species is divided into two cultivated types. One is P. frutescens var. frutescens that is a kind of oil crop. It is called by different names in East Asia countries, such as Ren in China, Dlggae in Korea, and Egoma in Japan. The other is $P$. frutescens var. crispa, a Chinese medicine or vegetable crop that is called Zisu in Chinese, Cha-jo-ki in Korean, and Shiso in Japanese (Lee and Ohnishi, 2003). P. frutescens var. frutescens is also used as a vegetable only in Korea, and its seeds are traditionally used in the same way that sesame seeds are used as a seasoning in China, Korea, and Japan from old times. On the other hand, P. frutescens var. crispa is used as Chinese medicine in East Asia from old times and is used as a spicy vegetable or pickle crop in Japan. Thus, these two cultivated types of Perilla crop have been important in East Asia from ancient times (Lee and Ohnishi, 2003; Nitta et al., 2003).

Since Perilla crop has been extensively cultivated and used in East Asia from old times, the original birth place of Perilla crop has generally been considered as East Asia (Makino et al., 1961; Li, 1969; Nitta, 2001) although the wild ancestor of cultivated types of Perilla crop has not yet been identified in East Asia. In East Asia, the cultivated var. frutescens is currently the most grown and is used as both an oil crop and a leafy vegetable in Korea. However, the cultivated var. crispa is not currently being cultivated because of the decreased use of Chinese medicine, although it is occasionally found as a relict form in Korea (Lee and Ohnishi, 2001; Lee et al., 2002). Conversely, the cultivated var. crispa is extensively cultivated and used in Japan, while the cultivated var. frutescens is rarely cultivated in Japan. On the other hand, the cultivated var. frutescens is grown in the northern area of China. Likewise, the cultivated var. crispa is not currently being cultivated in China. Because there have been very few efforts to improve Perilla crop through breeding programs, many genotypes of Perilla crop still occur as landraces in farmers' fields in East Asia (Lee et al., 2002). A landrace may be defined as active population(s) of a cultivated crop that has a distinct identity and lacks formal crop improvement, as well as often being genetically diverse, locally adapted, and associated with traditional farming systems (Harlan, 1975; Villa et al., 2006). Landraces may evolve through natural hybridization with closely wild or weedy relatives, and farmers play a critical role in selecting and adapting new materials using traditional skills and genetic resources (Zeven, 1998).

Genetics and Molecular Research 16 (3): gmr16039746 
Previously, various molecular markers have provided useful information regarding genetic diversity and genetic relationships in many crops (Senior et al., 1998; Nitta and Ohnishi, 1999; Prasad et al., 2000; Lee et al., 2002; Hamza et al., 2004; Xia et al., 2005; Lee and Kim, 2007; Sa et al., 2013, 2015; Park et al., 2002, 2015). Among them, random amplified polymorphic DNA or RAPD (Nitta and Ohnishi, 1999), amplified fragment length polymorphism or AFLP (Lee et al., 2002; Lee and Ohnishi, 2003), and simple sequence repeats or SSR (Lee and Kim, 2007; Park et al., 2008; Sa et al., 2013, 2015) markers have been applied in the analysis of genetic diversity and relationships among cultivated and weedy types of Perilla crop in East Asia and other countries. Particularly, SSR markers are highly reproducible, polymorphic, generally codominant, and abundant in plant genomes (Powell et al., 1996; Park et al., 2009). As a result of these better features, SSRs have been used to establish genetic diversity and genetic relationships in many crop species (da Cunha et al., 2014; Liu et al., 2014; Yook et al., 2014).

Identification of genetic variation is an essential ability for the long-term success of breeding programs and maximizes the use of germplasm resources (Rao, 2004). China has a long history of the cultivation of Perilla crop in East Asia, but there has been little research on the genetic diversity of accessions of Perilla crop. Therefore, the objective of this study was to establish the genetic diversity of Perilla crop from the northern areas of China based on SSR markers. The findings in this study can play an important role in the protection and conservation of accessions of Perilla species in China.

\section{MATERIAL AND METHODS}

\section{Plant materials and DNA extraction}

Seventy-seven accessions of $P$. frutescens were collected in different provinces of China in the year 2015. The accession numbers and localities of Perilla crop are shown in Table 1 and Figure 1. Seventy-seven accessions included 54 accessions of the cultivated type of the var. frutescens from high-latitude areas (northeastern regions of China) and 23 accessions of the cultivated type of the var. frutescens from middle-latitude areas (Northwest and North China). Only 3 accessions of the cultivated type of the var. crispa were collected in this study. The subset of each collection was deposited in the National Agrobiodiversity Center, Rural Development and Administration, Jeonju, Republic of Korea, for permanent seed preservation. These Perilla seeds collected were germinated on Petri dishes. The germinated seeds were sown in a nursery in May of 2016. After seedlings have come out, they were transplanted into the farm of Kangwon National University. Total DNA was extracted from the leaf tissues of a representative individual plant for each accession following the Plant DNAzol Reagent protocol (GibcoBRL Inc., Grand Island, NY, USA).

\section{SSR analysis and silver staining}

SSR amplifications were conducted in a total volume of $20 \mu \mathrm{L}$ consisting of $20 \mathrm{ng}$ genomic DNA, 1X PCR buffer, $0.5 \mu \mathrm{M}$ forward and reverse primers, $0.2 \mathrm{mM}$ dNTPs, and 1 $\mathrm{U}$ Taq polymerase (Biotools, Spain). The PCR profile consisted of initial denaturation at $95^{\circ} \mathrm{C}$ for $3 \mathrm{~min}$, followed by 36 cycles of $95^{\circ} \mathrm{C}$ for $30 \mathrm{~s}, 55^{\circ} \mathrm{C}$ for $30 \mathrm{~s}$, and $72^{\circ} \mathrm{C}$ for $1 \mathrm{~min} 30 \mathrm{~s}$, with a final extension step of $5 \mathrm{~min}$ at $72^{\circ} \mathrm{C}$. After PCR, $5 \mu \mathrm{L}$ the final products were mixed

Genetics and Molecular Research 16 (3): gmr16039746 
Table 1. Perilla accessions from different regions of China used for SSR analysis.

\begin{tabular}{|c|c|c|c|c|}
\hline Code No. & Accession No. & City and Province & Country & Type \\
\hline 1 & CH1 & Harbin, Hei Longjiang & CHN & Cultivated type of var. frutescens \\
\hline 2 & CH3 & Harbin, Hei Longjiang & $\mathrm{CHN}$ & Cultivated type of var. frutescens \\
\hline 3 & $\mathrm{CH} 35$ & Hailin, Hei Longjiang & CHN & Cultivated type of var. frutescens \\
\hline 4 & CH38 & Jiamusi, Hei Longjiang & CHN & Cultivated type of var. frutescens \\
\hline 5 & CH46 & Heihe, Hei Longjiang & CHN & Cultivated type of var. frutescens \\
\hline 6 & CH56 & Helong, Jilin & CHN & Cultivated type of var. frutescens \\
\hline 7 & CH58 & Helong, Jilin & CHN & Cultivated type of var. frutescens \\
\hline 8 & CH60 & Helong, Jilin & CHN & Cultivated type of var. frutescens \\
\hline 9 & CH62 & Helong, Jilin & CHN & Cultivated type of var. frutescens \\
\hline 10 & CH63 & Helong, Jilin & CHN & Cultivated type of var. frutescens \\
\hline 11 & CH64 & Helong, Jilin & CHN & Cultivated type of var. frutescens \\
\hline 12 & CH65 & Helong, Jilin & CHN & Cultivated type of var. frutescens \\
\hline 13 & CH66 & Helong, Jilin & CHN & Cultivated type of var. frutescens \\
\hline 14 & CH67 & Helong, Jilin & CHN & Cultivated type of var. frutescens \\
\hline 15 & CH68 & Helong, Jilin & $\mathrm{CHN}$ & Cultivated type of var. frutescens \\
\hline 16 & CH69 & Helong, Jilin & CHN & Cultivated type of var. frutescens \\
\hline 17 & CH70 & Helong, Jilin & CHN & Cultivated type of var. frutescens \\
\hline 18 & CH71 & Yanji, Jilin & CHN & Cultivated type of var. frutescens \\
\hline 19 & CH72 & Yanji, Jilin & CHN & Cultivated type of var. frutescens \\
\hline 20 & $\mathrm{CH} 73$ & Yanji, Jilin & $\mathrm{CHN}$ & Cultivated type of var. frutescens \\
\hline 21 & CH75 & Yanji, Jilin & $\mathrm{CHN}$ & Cultivated type of var. frutescens \\
\hline 22 & CH78 & Yanji, Jilin & CHN & Cultivated type of var. frutescens \\
\hline 23 & CH79 & Yanji, Jilin & CHN & Cultivated type of var. frutescens \\
\hline 24 & CH45 & Yanji, Jilin & CHN & Cultivated type of var. frutescens \\
\hline 25 & CH80 & Longjing, Jilin & CHN & Cultivated type of var. frutescens \\
\hline 26 & CH81 & Longjing, Jilin & $\mathrm{CHN}$ & Cultivated type of var. frutescens \\
\hline 27 & CH82 & Longjing, Jilin & CHN & Cultivated type of var. frutescens \\
\hline 28 & CH83 & Longjing, Jilin & CHN & Cultivated type of var. frutescens \\
\hline 29 & CH85 & Longjing, Jilin & CHN & Cultivated type of var. frutescens \\
\hline 30 & $\mathrm{CH} 86$ & Longjing, Jilin & $\mathrm{CHN}$ & Cultivated type of var. frutescens \\
\hline 31 & CH87 & Longjing, Jilin & CHN & Cultivated type of var. frutescens \\
\hline 32 & CH88 & Longjing, Jilin & CHN & Cultivated type of var. frutescens \\
\hline 33 & CH16 & Longjing, Jilin & CHN & Cultivated type of var. frutescens \\
\hline 34 & CH17 & Longjing, Jilin & CHN & Cultivated type of var. frutescens \\
\hline 35 & $\mathrm{CH} 20$ & Longjing, Jilin & CHN & Cultivated type of var. frutescens \\
\hline 36 & $\mathrm{CH} 22$ & Longjing, Jilin & CHN & Cultivated type of var. frutescens \\
\hline 37 & $\mathrm{CH} 23$ & Longjing, Jilin & CHN & Cultivated type of var. frutescens \\
\hline 38 & CH13 & Changchun, Jilin & CHN & Cultivated type of var. frutescens \\
\hline 39 & CH24 & Baishan, Jilin & CHN & Cultivated type of var. frutescen \\
\hline 40 & $\mathrm{CH} 32$ & Changbai, Jilin & $\mathrm{CHN}$ & Cultivated type of var. frutescens \\
\hline 41 & $\mathrm{CH} 33$ & Tonghua, Jilin & CHN & Cultivated type of var. frutescens \\
\hline 42 & CH43 & Tonghua, Jilin & CHN & Cultivated type of var. frutescens \\
\hline 43 & CH14 & Siping, Jilin & CHN & Cultivated type of var. frutescens \\
\hline 44 & $\mathrm{CH} 42$ & Jilin, Jilin & CHN & Cultivated type of var. frutescens \\
\hline 45 & CH27 & Jilin, Jilin & CHN & Cultivated type of var. frutescens \\
\hline 46 & CH28 & Jilin, Jilin & CHN & Cultivated type of var. frutescens \\
\hline 47 & $\mathrm{CH} 4$ & Shenyang, Liaoning & $\mathrm{CHN}$ & Cultivated type of var. frutescens \\
\hline 48 & CH5 & Shenyang, Liaoning & $\mathrm{CHN}$ & Cultivated type of var. frutescens \\
\hline 49 & CH7 & Liaoyang, Liaoning & $\mathrm{CHN}$ & Cultivated type of var. frutescens \\
\hline 50 & CH8 & Liaoyang, Liaoning & CHN & Cultivated type of var. frutescens \\
\hline 51 & CH11 & Tianjin & CHN & Cultivated type of var. frutescens \\
\hline 52 & CH34 & Zhengzhou, Henan & CHN & Cultivated type of var. frutescens \\
\hline 53 & CH37 & Tianshui, Gansu & CHN & Cultivated type of var. frutescens \\
\hline 54 & $\mathrm{CH} 30$ & Tianshui, Gansu & CHN & Cultivated type of var. frutescens \\
\hline 55 & CH39 & Tianshui, Gansu & CHN & Cultivated type of var. frutescens \\
\hline 56 & CH49 & Pingliang, Gansu & CHN & Cultivated type of var. frutescens \\
\hline 57 & CH55 & Longnan, Gansu & CHN & Cultivated type of var. frutescens \\
\hline 58 & $\mathrm{CH} 40$ & Longnan, Gansu & CHN & Cultivated type of var. frutescens \\
\hline 59 & CH29 & Longnan, Gansu & CHN & Cultivated type of var. frutescens \\
\hline 60 & CH51 & Qingyang, Gansu & CHN & Cultivated type of var. frutescens \\
\hline 61 & $\mathrm{CH} 41$ & Haozhou, Anhui & CHN & Cultivated type of var. frutescens \\
\hline 62 & CH44 & Haozhou, Anhui & $\mathrm{CHN}$ & Cultivated type of var. frutescens \\
\hline 63 & CH50 & Suqian, Jiangsu & CHN & Cultivated type of var. frutescens \\
\hline 64 & CH31 & Huai'an, Jiangsu & CHN & Cultivated type of var. frutescens \\
\hline 65 & $\mathrm{CH} 26$ & Jilin, Jilin & $\mathrm{CHN}$ & Cultivated type of var. frutescens \\
\hline 66 & CH12 & Changchun, Jilin & CHN & Cultivated type of var. frutescens \\
\hline 67 & CH6 & Shenyang, Liaoning & CHN & Cultivated type of var. frutescens \\
\hline 68 & CH10 & Anguo, Hebei & $\mathrm{CHN}$ & Cultivated type of var. frutescens \\
\hline 69 & $\mathrm{CH} 48$ & Tianshui, Gansu & CHN & Cultivated type of var. frutescens \\
\hline 70 & CH9 & Cangzhou, Hebei & CHN & Cultivated type of var. frutescens \\
\hline 71 & CH25 & Weifang, Shandong & CHN & Cultivated type of var. frutescens \\
\hline 72 & CH36 & Zhengzhou, Henan & CHN & Cultivated type of var. frutescens \\
\hline 73 & CH47 & Baoding, Hebei & CHN & Cultivated type of var. frutescens \\
\hline 74 & CH52 & Yantai, Shandong & CHN & Cultivated type of var. crispa \\
\hline 75 & $\mathrm{CH} 2$ & Harbin, Hei Longjiang & CHN & Cultivated type of var. crispa \\
\hline 76 & CH54 & Zhaoyuan, Shandong & $\mathrm{CHN}$ & Cultivated type of var. crispa \\
\hline 77 & CH53 & Zhaoyuan, Shandong & $\mathrm{CHN}$ & Cultivated type of var. crispa \\
\hline
\end{tabular}

with $10 \mu \mathrm{L}$ electrophoresis loading buffer (98\% formamide, $0.02 \% \mathrm{BPH}, 0.02 \%$ Xylene $\mathrm{C}$, and $5 \mathrm{mM} \mathrm{NaOH}$ ). After denaturing and quick cooling, $2 \mu \mathrm{L}$ of each sample was loaded onto $6 \%$ denaturing (7.5 M urea) acrylamide-bisacrylamide gel (19:1) in 1X TBE buffer and

Genetics and Molecular Research 16 (3): gmr16039746 
then electrophoresed at $1800 \mathrm{~V}$ and $60 \mathrm{~W}$ for $130 \mathrm{~min}$. The separated fragments were then visualized using a silver staining kit (Promega, Madison, WI, USA).

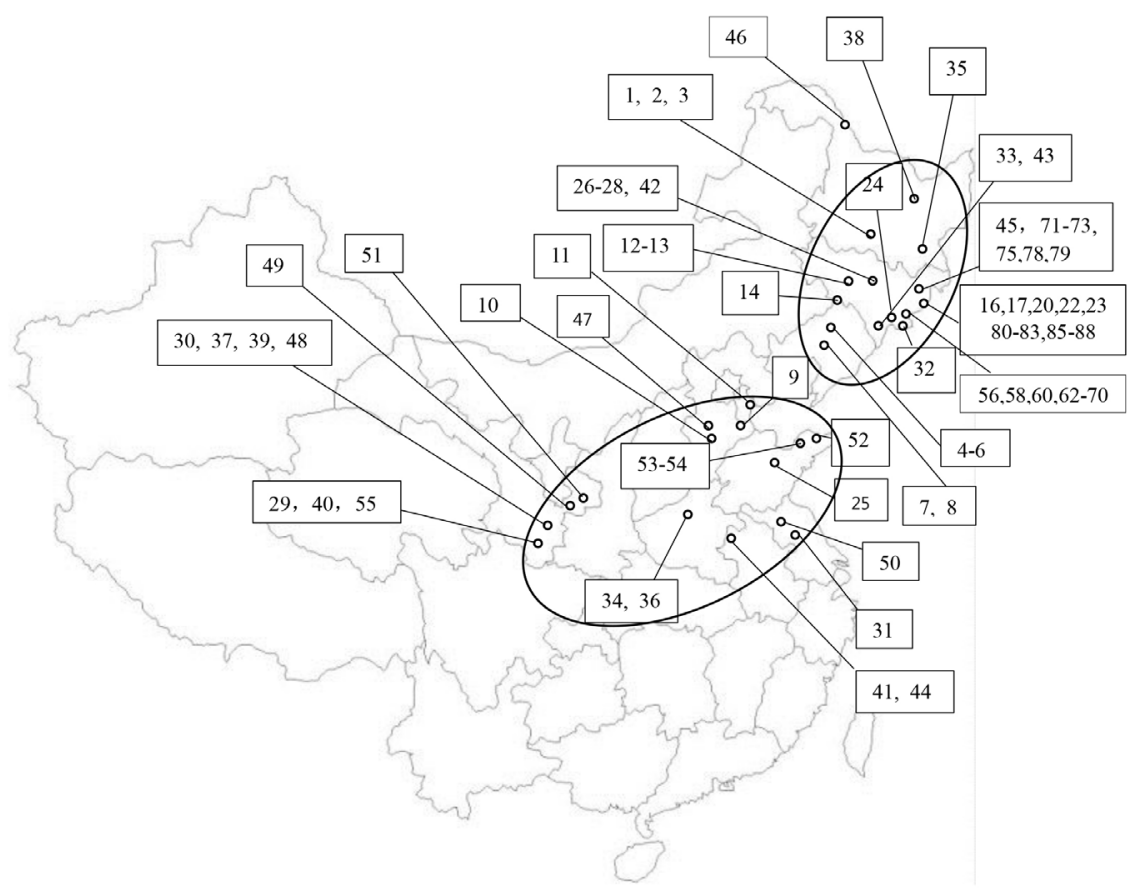

Figure 1. Collecting sites of accessions of cultivated types of Perilla crop were evaluated in this study. Perilla accessions collected from high-latitude area and middle-latitude area were respectively shown in the upper and lower oval circles.

\section{Data analysis}

Fragments amplified using the SSR primers were scored as presence (1) or absence (0). Power Marker version 3.25 (Liu and Muse, 2005) was applied to obtain the information on the number of alleles, allele frequency, major allele frequency (MAF), gene diversity (GD), and polymorphic information content (PIC). Genetic similarities were calculated for each pair of lines using the Dice similarity index (Dice, 1945). To illustrate the genetic relationship of samples, the similarity matrix was then used to construct an unweighted pair group method with arithmetic mean (UPGMA) dendrogram by the application of SAHN-Clustering from NTSYS-pc.V.2.1 (Rohlf, 1998). The STRUCTURE 2.2 software (Pritchard and Wen, 2003) was used for the investigation of a population structure of 77 accessions of Perilla crop. To identify the number of clusters $(\mathrm{K})$, the software was run using admixture model with correlated allele frequencies following Hardy-Weinberg equilibrium. Five independent runs were performed for each simulated value of $\mathrm{K}=1$ to 10 , with a burn-in period of 100,000 runs followed by 100,000 Monte Carlo Markov Chain (MCMC) replications. The real number of population was detected by plotting $\mathrm{Ln}(\mathrm{PD})$ derived $\Delta \mathrm{K}$, an ad hoc quantity against each $\mathrm{K}$ (Evanno et al., 2005). The result was computed and visualized using the Structure Harvester software (http://taylor0.biology.ucla.edu/struct_harvest/).

Genetics and Molecular Research 16 (3): gmr16039746 


\section{RESULTS}

\section{SSR polymorphism and genetic variation among Perilla accessions from different regions of China}

The genetic variability at each SSR locus was measured regarding the number of alleles, MAF, GD, and PIC (Table 2). A total of 21 SSR loci showed polymorphism, producing a total of 95 alleles among the 77 accessions of Perilla crop. The number of alleles per locus varied widely from 2 at GBPF201, KWPE32, and KWPE56 to 11 at GBPF204, with an average of 4.52 alleles. The MAF per locus varied from 0.442 (GBPF204) to 0.948 (GBPF201, GBPF91), with an average of 0.746 . The GD of each locus ranged from 0.098 at GBPF201 to 0.741 at GBPF204, with an average of 0.372 (Table 2). The PIC values ranged from 0.094 at GBPF201 to 0.714 at GBPF204, with an average of 0.346 (Table 2).

Table 2. Characteristics of the 21 SSR loci including primer sequence, repeat motif, allele size range, allele numbers, major allele frequency, gene diversity, and PIC among 77 accessions of Perilla crop from different regions of China.

\begin{tabular}{|c|c|c|c|c|c|c|c|}
\hline SSR loci & Primer sequence & Repeat motif & Allele size (bp) & No. of alleles & MAF & GD & PIC \\
\hline GBPF201 & $\begin{array}{l}\text { F-AGACTCGTTTCACAATTTCTCC } \\
\text { R-CATTCCCACCTCATGTTACG }\end{array}$ & $\begin{array}{c}(\mathrm{GA})_{6}(\mathrm{GT}) \\
(\mathrm{GA})_{5}\end{array}$ & $150-155$ & 2 & 0.948 & 0.098 & 0.094 \\
\hline GBPF179 & $\begin{array}{l}\text { F-TGAATCATCCCAAACGAGAT } \\
\text { R-TCGCTTCTCTCTCATGGATT }\end{array}$ & $(\mathrm{TGA})_{5}$ & $170-182$ & 5 & 0.623 & 0.565 & 0.528 \\
\hline GBPF172 & $\begin{array}{l}\text { F-ATCGGTCTTTGAAATCACCA } \\
\text { R-TGAAATTTCTTGCCGTTACC }\end{array}$ & $(\mathrm{GA})_{11}$ & $260-276$ & 3 & 0.636 & 0.517 & 0.452 \\
\hline GBPF135 & $\begin{array}{l}\text { F-CTTCTGAGGCCAACATTGAG } \\
\text { R-AGGGCTCGGTTGAATCTTAC }\end{array}$ & $(\mathrm{CT})_{20}$ & $190-216$ & 5 & 0.909 & 0.171 & 0.168 \\
\hline GBPF75 & $\begin{array}{l}\text { F-CATAGTTCATGGCTTCCACC } \\
\text { R-CCTGAGCACAGAAACAGATCA }\end{array}$ & $(\mathrm{CT})_{12}$ & $147-153$ & 3 & 0.922 & 0.146 & 0.141 \\
\hline GBPF70 & $\begin{array}{l}\text { F-CCCTCCAAATCAATATTCCA } \\
\text { R-TAGCTGCCATACGAACATGA }\end{array}$ & $(\text { ATTTG })_{3},(\mathrm{AC})_{5}$ & $215-240$ & 4 & 0.922 & 0.148 & 0.144 \\
\hline KWPE25 & $\begin{array}{l}\text { F-ACATTTAAGAGAGAGAGCAAG } \\
\text { R-ACGAACGGGCTTCAATCTT }\end{array}$ & {$\left[(\mathrm{GT})_{8}(\mathrm{GA})_{14}\right]$} & $213-220$ & 3 & 0.896 & 0.191 & 0.182 \\
\hline KWPE26 & $\begin{array}{l}\text { F-GAGGCAATGCTGGTACTTC } \\
\text { R-GAACGGGCTTCAATCTTC }\end{array}$ & {$\left[(\mathrm{AG})_{6}(\mathrm{AG})_{7}(\mathrm{GA})_{13}\right]$} & $235-245$ & 3 & 0.909 & 0.169 & 0.162 \\
\hline KWPE32 & $\begin{array}{l}\text { F-AGAACAACATTGTAGCTCGG } \\
\text { R-ACGACCAACCAGTAGATGAT }\end{array}$ & $(\mathrm{CCT})_{4}$ & $148-154$ & 2 & 0.883 & 0.206 & 0.185 \\
\hline KWPE39 & $\begin{array}{l}\text { F-AGAACAACATTGTAGCTCGG } \\
\text { R-GACGAACCAGCAAACGAC }\end{array}$ & $(\mathrm{CCT})_{4}$ & $330-400$ & 4 & 0.545 & 0.598 & 0.533 \\
\hline KWPE48 & $\begin{array}{l}\text { F-CACCCCATCTTTTTGGAT } \\
\text { R-AGCAGGATGGTGGTGGTC }\end{array}$ & $(\mathrm{GA})_{9}$ & $215-226$ & 3 & 0.896 & 0.192 & 0.183 \\
\hline KWPE57 & $\begin{array}{l}\text { F-ATCACATCTCTCTCTTTCTGGA } \\
\text { R-CCAGTCACTCCATCATCTCTA }\end{array}$ & $(\mathrm{CT})_{16}$ & $155-181$ & 8 & 0.468 & 0.721 & 0.692 \\
\hline KWPE56 & $\begin{array}{l}\text { F-AAGCAGTGGACTGATTGTTT } \\
\text { R-ACAAAATCCAATTACTTTCTGC }\end{array}$ & (TG)9 & $105-107$ & 2 & 0.506 & 0.500 & 0.375 \\
\hline KWPE53 & $\begin{array}{l}\text { F-ACTCACCAGAAGAGAAGAAGA } \\
\text { R-GCCACTGACCTGTTAATATCTG }\end{array}$ & $(\mathrm{CT})_{16}$ & $194-224$ & 6 & 0.667 & 0.512 & 0.482 \\
\hline KWPE58 & $\begin{array}{l}\text { F-AGAGAGTTACCTGCGATTTTC } \\
\text { R-CTTCAATATTCGGCCATCTT }\end{array}$ & $(\mathrm{TG})_{9}(\mathrm{AG})_{12}$ & $163-175$ & 5 & 0.870 & 0.238 & 0.232 \\
\hline KWPE19 & $\begin{array}{l}\text { F-CAACCCTTCACGATCACTAT } \\
\text { R-AAATAACGGCCGATTCTAC }\end{array}$ & $(\mathrm{ACG})_{7}$ & $250-271$ & 6 & 0.688 & 0.498 & 0.471 \\
\hline KWPE29 & $\begin{array}{l}\text { F-AAGACAAGGAGGAAGATGC } \\
\text { R-ATAGGTGTTCGCTCTCCTGTG }\end{array}$ & $(\text { GAA })_{5}$ & $210-245$ & 7 & 0.532 & 0.664 & 0.632 \\
\hline GBPF111 & $\begin{array}{l}\text { F-ATCATGGATGAATCGCACTT } \\
\text { R-CATTCTCCAAATGTTACTCTATTT }\end{array}$ & $(\mathrm{ACACA})_{8}$ & $161-200$ & 6 & 0.857 & 0.259 & 0.250 \\
\hline GBPF155 & $\begin{array}{l}\text { F-TTTGTGACAATACGCACCAC } \\
\text { R-CCAATTGCTCAATGCTCTCT }\end{array}$ & $(\mathrm{GAA})_{10}$ & $281-305$ & 4 & 0.597 & 0.587 & 0.545 \\
\hline GBPF204 & $\begin{array}{l}\text { F-TCGAAAAATTGCAGATCACC } \\
\text { R-TTGTCTTTTGCCTCTTTTGC }\end{array}$ & $(\mathrm{AG})_{17}$ & $130-144$ & 11 & 0.442 & 0.741 & 0.714 \\
\hline GBPF91 & $\begin{array}{l}\text { F-CCACTCAAATCCGCTTCTAA } \\
\text { R-AATGTTGGTTGCGTTTCATT }\end{array}$ & $(\mathrm{AG}) 9$ & $221-230$ & 3 & 0.948 & 0.100 & 0.096 \\
\hline Average & & & & 4.52 & 0.746 & 0.372 & 0.346 \\
\hline
\end{tabular}

MAF: major allele frequency; GD: genetic diversity; PIC: polymorphic information content.

Genetics and Molecular Research 16 (3): gmr16039746 
To compare the genetic diversity of the cultivated var. frutescens between highlatitude (53 accessions) and middle-latitude (20 accessions) regions in northern China, we also measured the number of alleles, MAF, GD, and PIC among the 73 accessions of the cultivated var. frutescens (Table 3). The average number of alleles was 3.52 and 3.19 alleles for accessions of the cultivated var. frutescens from high-latitude and middle-latitude areas in northern China, respectively. The average GD was 0.266 and 0.410 for accessions of the cultivated var. frutescens from high-latitude and middle-latitude areas in northern China, respectively. Finally, the average PIC values were 0.246 and 0.373 for accessions of the cultivated var. frutescens from high-latitude and middle-latitude areas in northern China, respectively (Table 3). These results show that accessions of the cultivated var. frutescens from middle-latitude area exhibited higher GD and PIC values than those of the cultivated var. frutescens from high-latitude areas.

\begin{tabular}{l} 
Table 3. Number of alleles, genetic diversity, and polymorphic information content obtained from each SSR locus \\
in accessions of the cultivated var. frutescens collected from high-latitude and middle-latitude areas of China. \\
\begin{tabular}{l|l|l|l|l|c} 
Accessions of cultivated var. frutescens \\
Markers
\end{tabular} \\
\cline { 2 - 7 } \\
\cline { 2 - 7 } \\
\cline { 2 - 7 }
\end{tabular}

GD: genetic diversity; PIC: polymorphic information content.

\section{Genetic relationships among accessions of Perilla crop from different regions of China}

The phylogenetic tree was constructed using UPGMA and revealed that 77 Perilla accessions were clustered into four major groups with a genetic similarity of $46 \%$ (Figure 2). Group I contained 69 accessions of the cultivated var. frutescens. Group II contained 2 accessions of the cultivated var. frutescens and 1 accession of the cultivated var. crispa (CH53). Group III contained only 2 accessions of the cultivated var. frutescens. Group IV contained only 3 accessions of the cultivated var. crispa. Besides, accessions in Group I were further subdivided into four sub-clusters with a genetic similarity of $60 \%$. The first sub-cluster contained 4 accessions of the cultivated var. frutescens from high-latitude areas and 1 accession of the cultivated var. frutescens from middle-latitude areas. The second sub-cluster contained 
56 accessions of the cultivated var. frutescens from high-latitude (47 accessions) and middlelatitude ( 9 accessions) areas. The third sub-cluster contained 5 accessions of the cultivated var. frutescens from middle-latitude areas and 1 accession of the cultivated var. frutescens from high-latitude areas. The fourth sub-cluster contained 2 accessions of the cultivated var. frutescens from high-latitude and middle-latitude areas, respectively.

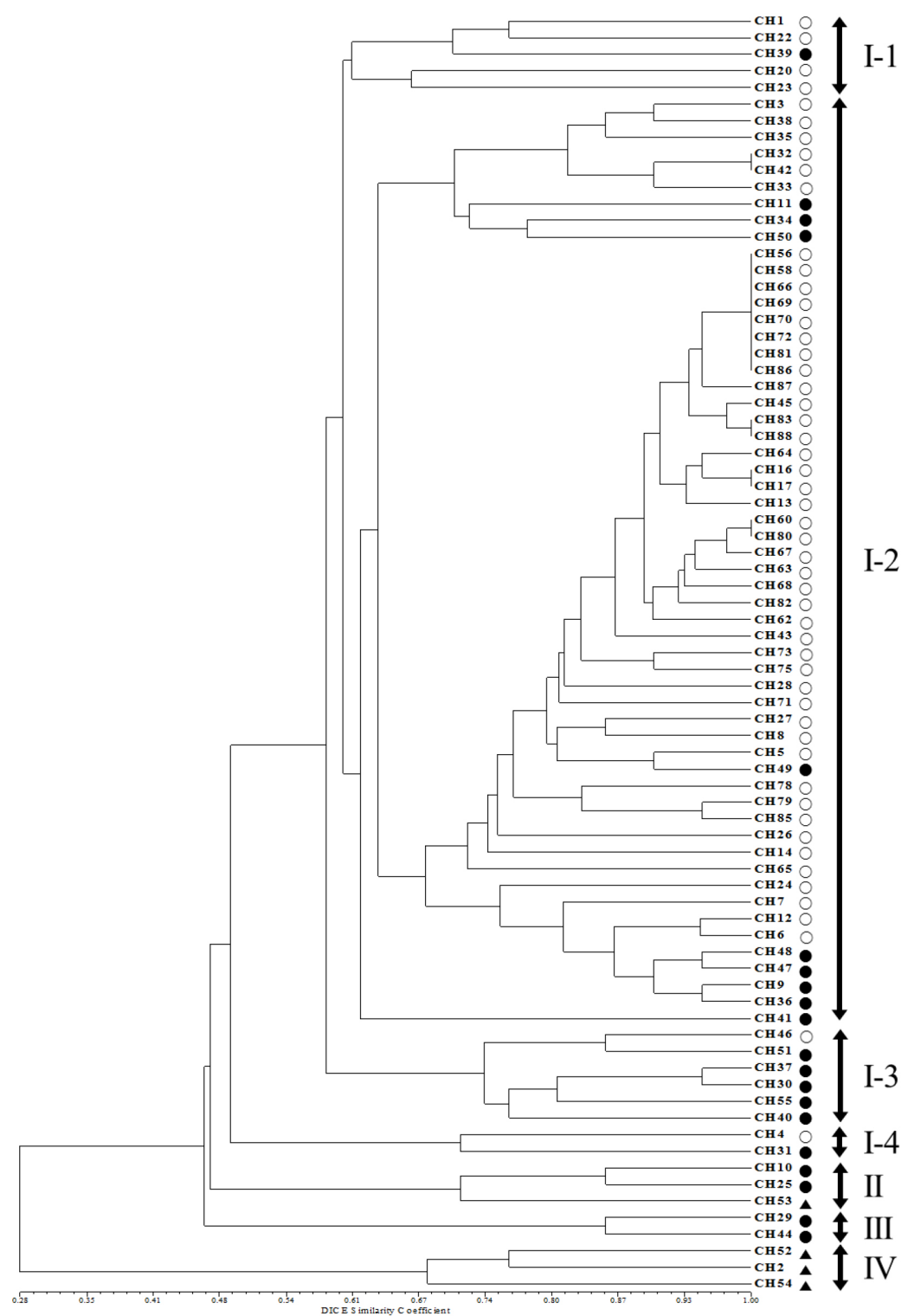

Figure 2. UPGMA dendrogram based on the SSR markers. The accessions of Perilla crop from high-latitude and middle-latitude areas of China are shown in Table 1. Open circle: cultivated var. frutescens from high-latitude area, filled circle: cultivated var. frutescens from middle -latitude area, filled triangle: cultivated var. crispa.

Genetics and Molecular Research 16 (3): gmr16039746 
In our analysis, all accessions of the cultivated var. frutescens were discriminated from the cultivated var. crispa, except for one accession (CH53), which belonged to the group of the cultivated var. frutescens. Furthermore, in the case of the cultivated var. frutescens, most accessions of the cultivated var. frutescens collected in high-latitude and middle-latitude areas were distinguished depending on their geographical location, except for several accessions.

\section{Population structure}

To understand the genetic structure among the 77 Perilla accessions from highlatitude and middle-latitude areas in northern China, we used a model-based approach in the STRUCTURE software to subdivide each accession into their corresponding subgroups. We ran STRUCTURE for fixed $\mathrm{K}$ values ranging from one to ten and performed five runs for each $\mathrm{K}$. This study applied the ad hoc measure $\Delta \mathrm{K}$ using the method developed by Evanno et al. (2005) to overcome the difficulty in interpreting the real $\mathrm{K}$ values. The highest value of $\Delta \mathrm{K}$ for the 77 Perilla accessions was for $\mathrm{K}=2$ (Figure 3).

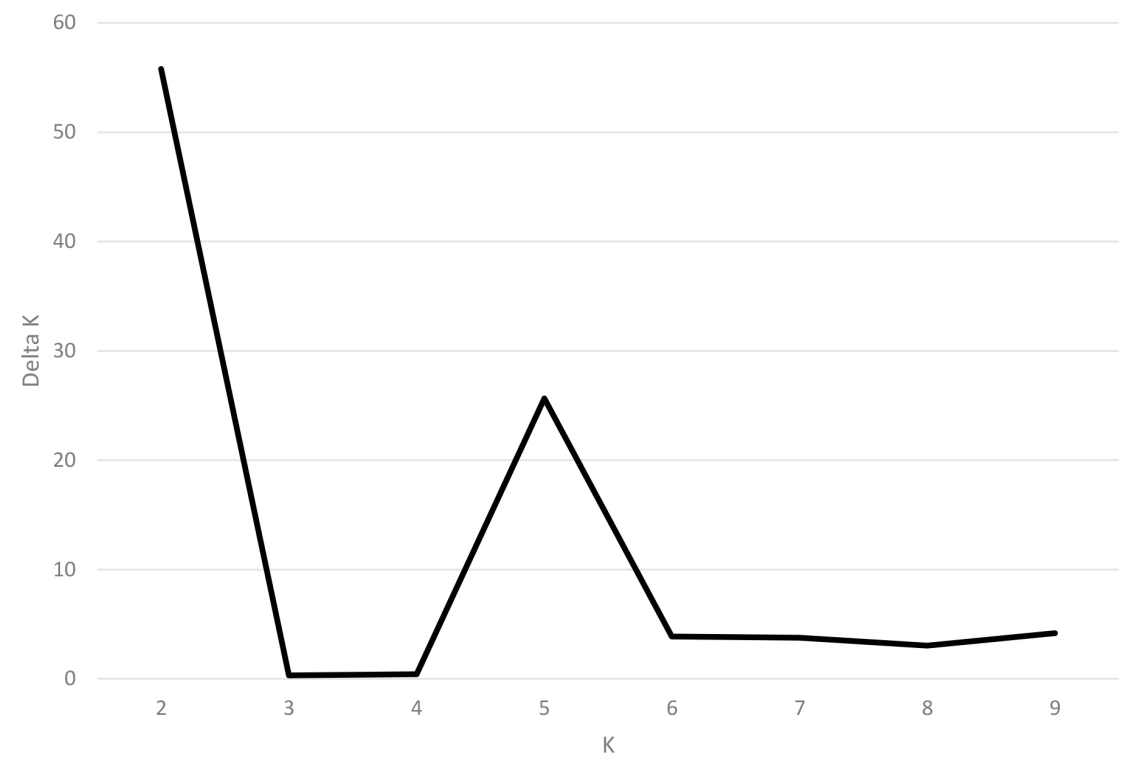

Figure 3. Magnitude of $\Delta K$ as a function of $K$. The peak value of $\Delta K$ was at $K=2$, suggesting two genetic clusters in the Perilla accessions from high-latitude and middle-latitude areas of China.

Clustering bar plots with $\mathrm{K}=2$ are shown in Figure 4. At K=2, all 77 Perilla accessions were divided into two groups. However, some Perilla accessions were admixed within these two groups. There was no clear geographic structure among the 77 Perilla accessions from high-latitude and middle-latitude regions in northern China, which was confirmed by UPGMA analysis (Figures 2 and 4). Therefore, we performed an analysis according to the method of Wang et al. (2008) based on a membership probability threshold of 0.8. As a result, the 77 Perilla accessions were divided into Group I, Group II, and an admixed group. Group I included 25 accessions (CH56, CH58, CH60, CH62, CH63, CH64, CH66, CH67, CH68,

Genetics and Molecular Research 16 (3): gmr16039746 
$\mathrm{CH} 69, \mathrm{CH} 70, \mathrm{CH} 72, \mathrm{CH} 75, \mathrm{CH} 45, \mathrm{CH} 80, \mathrm{CH} 81, \mathrm{CH} 82, \mathrm{CH} 83, \mathrm{CH} 86, \mathrm{CH} 87, \mathrm{CH} 88, \mathrm{CH} 13$, $\mathrm{CH} 16, \mathrm{CH} 17, \mathrm{CH} 43)$ of the cultivated var. frutescens from high-latitude areas of China. Group II included 16 accessions (CH30, CH34, CH37, CH39, CH46, CH55, CH40, CH29, $\mathrm{CH} 51, \mathrm{CH} 44, \mathrm{CH} 31, \mathrm{CH} 6, \mathrm{CH} 9, \mathrm{CH} 10, \mathrm{CH} 24, \mathrm{CH} 25)$ of the cultivated var. frutescens and 4 accessions (CH2, CH52, CH53, CH54) of the cultivated var. crispa. The admixed group comprised 25 accessions (CH1, CH3, CH35, CH38, CH65, CH71, CH73, CH78, CH79, $\mathrm{CH} 85, \mathrm{CH} 20, \mathrm{CH} 22, \mathrm{CH} 23, \mathrm{CH} 32, \mathrm{CH} 33, \mathrm{CH} 14, \mathrm{CH} 42, \mathrm{CH} 26, \mathrm{CH} 12, \mathrm{CH} 27, \mathrm{CH} 28, \mathrm{CH} 4$, $\mathrm{CH} 5, \mathrm{CH} 7, \mathrm{CH} 8)$ of the cultivated var. frutescens from high-latitude areas of China and 7 accessions (CH11, CH49, CH41, CH50, CH36, CH47, CH48) of the cultivated var. frutescens from middle-latitude areas of China.

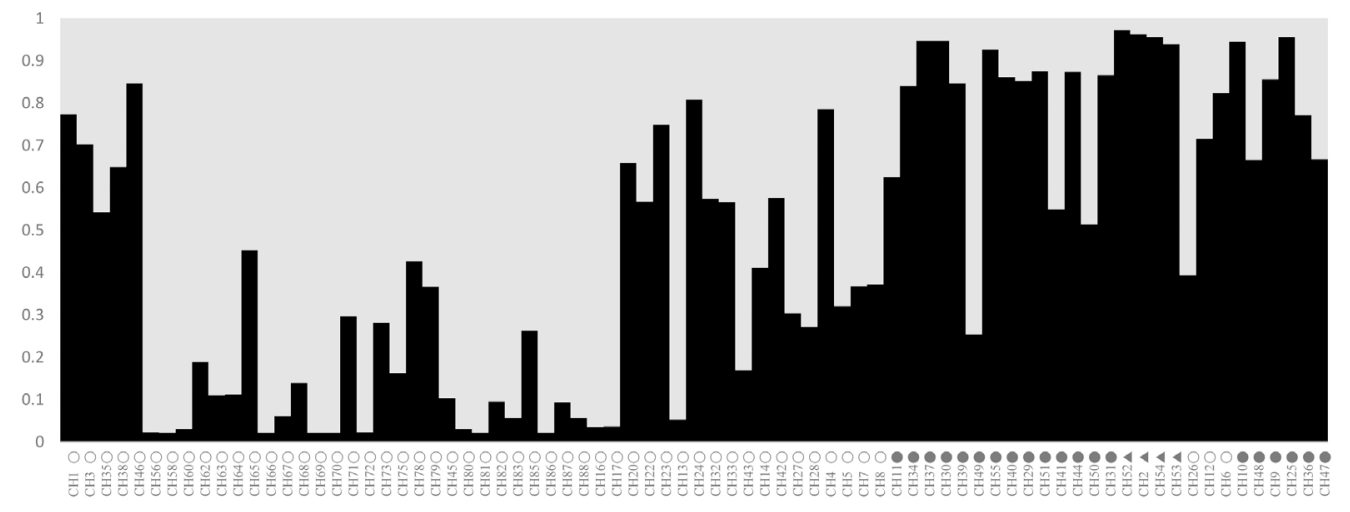

Figure 4. Population structure of 77 accessions of two cultivated types of Perilla crop based on 21 SSRs for K $=2$. Open circle: cultivated var. frutescens from high-latitude area, filled circle: cultivated var. frutescens from middle -latitude area, filled triangle: cultivated var. crispa.

\section{DISCUSSION}

Genetic diversity (or variation) is usually thought of as the amount of genetic variability among individuals of a variety or population of a species (Brown, 1983). It results from the many genetic differences between individuals and may be manifested in differences in DNA polymorphism (e.g., RFLP, RAPD, AFLP, and SSR markers), in biochemical characteristics (e.g., in protein structure or isoenzyme properties), in physiological properties (e.g., abiotic stress resistance or flowering habits), or in morphological characters such as seed color or plant height (Rao and Hodgkin, 2002). Morphological characters or physiological properties were the major methods for germplasm classification or genetic resource evaluation in previous studies. As a consequence of the effects of environmental conditions or other factors on the final results, classification or evaluation accuracy was usually reduced. To obtain an accurate germplasm evaluation, modern biotechnological tools at the DNA-based molecular markers have provided useful information regarding genetic diversity and genetic relationships. Among the various types of DNA molecular markers, SSR markers are useful for analysis in plant genetics, and ecology since the hypervariable nature of SSRs results in the production of high levels of allelic variations, even among very closely related individuals (Powell et al., 1996; Park et al., 2009). 
In this study, 21 SSR primer sets were applied for analysis of genetic diversity among Perilla accessions collected in high-latitude and middle-latitude areas of China. According to our results, a total of 95 alleles with 21 SSRs were detected segregating in the 77 Perilla accessions from different areas of China, which yielded an average of 4.52 alleles per locus. This value appears to be low when compared to the effective number of alleles per SSR locus in the results of previous studies by Lee and Kim (2007) and Sa et al. (2013). They detected a total of 101 alleles with 11 SSRs among 70 Perilla accessions from East Asia, with an average allele number of 9.2 per locus (Lee and Kim, 2007), and a total of 165 alleles using 18 SSR markers in 56 Perilla accessions from Korea and Japan with an average of 9.2 alleles yielded at each locus (Sa et al., 2013). Furthermore, the average value of genetic diversity in this study is much lower than the values of previous studies by Lee and Kim (2007) and Sa et al. (2013). The reason for the low values of genetic diversity and allele numbers per locus obtained in the current study might be attributed to different materials of Perilla accessions when compared with the previous studies by Lee and Kim (2007) and Sa et al. (2013). For example, most materials used in this study are accessions of the cultivated var. frutescens, and only 4 accessions of the cultivated var. crispa were collected from high-latitude and middlelatitude areas of China. Unfortunately, at the beginning of this study, we did not collect weedy accessions of two cultivated types of Perilla crop in these areas. While in the previous studies, they used many accessions of cultivated and weedy types of Perilla crop in East Asia (Lee and Kim, 2007; Sa et al., 2013). They reported that the accessions of two weedy types of Perilla crop had higher genetic diversity than accessions of two cultivated types of Perilla crop (Lee and Ohnishi, 2003; Lee and Kim, 2007; Sa et al., 2013). This result indicated that in domestication through direct and indirect human selections during the evolutionary stage from wild type to cultivated type, some alleles were lost, and the level of polymorphism and genetic diversity were reduced.

On the other hand, in case of the northern areas of China, accessions of the cultivated var. frutescens from middle-latitude areas, which had a smaller population size of materials compared to those collected from high-latitude areas, showed much higher genetic diversity and PIC values than those of the cultivated var. frutescens from high-latitude areas (Table 3). This result indicated that the cultivated var. frutescens from middle-latitude areas might have higher genetic diversity than that of the high-latitude areas. PIC was used to measure genetic diversity (Vaiman et al., 1994). PIC value was applied in the measurement of the efficiency of polymorphic loci. If PIC $>0.5,0.5>$ PIC $>0.25$, and $\mathrm{PIC}<0.25$, locus polymorphisms can be assessed as high, medium, and low, respectively (Xie et al., 2010). In this study, the average value of PIC was 0.346 , indicating that 21 SSR loci used in this study showed average level polymorphism for the accessions of Perilla crop from the northern areas of China. Meanwhile, the PIC values of 6 SSR loci, such as GBPF179, GBPF155, GBPF204, KWPE39, KWPE57, and KWPE29, showed more than 0.5 (Table 3). The five markers, GBPF155, GBPF204, KWPE39, KWPE57, and KWPE29, also showed the high values of PIC for the accessions of Perilla from East Asia and other countries (Sa et al., 2013, 2015; Woo et al., 2016). Therefore, these SSR markers were considered useful and highly informative for the analysis of genetic diversity in Perilla accessions from the northern areas of China and might be effectively applied in differentiating the polymorphic rate of a marker at a specific locus.

As shown in Figure 2,77 accessions of Perilla crop were divided into 4 main groups by the analysis of the UPGMA dendrogram. Most accessions of the cultivated var. crispa, except one accession (CH53), were obviously separated from the accessions of the cultivated

Genetics and Molecular Research 16 (3): gmr16039746 
var. frutescens. The result was consistent with the previous study by Sa et al. (2013). They reported that SSR markers are useful for distinguishing between two cultivated types of Perilla crop. However, one accession (CH53) of the cultivated var. crispa was situated in the group of the cultivated var. frutescens. Similar results have also been reported in the previous studies by Lee and Ohnishi (2003) and Sa et al. (2013). Namely, several accessions of var. frutescens and var. crispa were ambiguously classified on the basis of AFLP and SSR markers (Lee and Ohnishi, 2003; Sa et al., 2013). These results might be thought as a natural crossing that occurs between the two cultivated types of Perilla crop, as previously reported by Nitta and Ohnishi (1999) and Lee and Ohnishi (2001). By the result of the UPGMA dendrogram, most accessions of the cultivated var. frutescens collected from the middle-latitude area of China were classified from accessions of the cultivated var. frutescens from the high-latitude area of China. Based on the analysis of the population structure, Group I only consisted of accessions of the var. frutescens from high-latitude areas. Group II contained most Perilla accessions from middlelatitude areas except $\mathrm{CH} 6, \mathrm{CH} 24$, and $\mathrm{CH} 46$. However, the geographical locations of several accessions of the cultivated var. frutescens were not consistent with their positions in the UPGMA dendrogram and population structure. Similar results were also obtained with RAPD (Nitta and Ohnishi, 1999) and AFLP (Lee and Ohnishi, 2003) analysis. This result implies that the diffusion of accessions of the cultivated Perilla crop in the northern areas of China might be through multiple routes. Besides, an admixture of accessions of the cultivated Perilla crop from different areas of China was observed in Figure 4. The occurrence of this phenomenon may be attributed to the following factors. Firstly, overlapping distribution of Perilla accessions grown in the vicinity of the boundary between high-latitude and middle-latitude areas caused an occurrence of gene introgression among accessions in different regions. Second, the topography of areas where these accessions were collected was major in the plain. Gene flow happened through pollens, seeds, and other natural approaches easily in the plain areas, degrading the variation and leading to an unclear structure among cultivated Perilla accessions from different regions. Human activities may be the main reason for the ambiguous classification of these accessions. Gene flow can be influenced significantly by human activities (Meng et al., 2015). Seeds of accessions from high-latitude areas may be transferred to northwestern areas of China or other middle latitude areas via human business activities. Probably, the occurrence of this migration or introduction within same regions or between different regions caused these accessions to be categorized ambiguously under the analysis of UPGMA.

The investigations on genetic diversity, population structure, and collection and conservation of germplasm resources have benefited from the utility of SSR markers. The valuable information on the genetic structures and relationships of Perilla accessions from northern areas of China have been provided by using the 21 SSR markers in this study. Through the comprehensive analysis of genetic diversity, genetic relationship, and population structure among these Chinese Perilla resources, the basic genetic knowledge of Chinese Perilla has been obtained and can be used as a reference for genetic diversity studies, germplasm, conservation, and breeding strategies in the future.

\section{ACKNOWLEDGMENTS}

Research supported by the Basic Science Research Program through the National Research Foundation of Korea (NRF) funded by the Ministry of Education, Science, and Technology (\#2016R1D1A1B01006461).

Genetics and Molecular Research 16 (3): gmr16039746 


\section{REFERENCES}

Brown WL (1983). Genetic diversity and genetic vulnerability - an appraisal. Econ. Bot. 37: 4-12. https://doi.org/10.1007/ BF02859301

da Cunha CP, Resende FV, Zucchi MI and Pinheiro JB (2014). SSR-based genetic diversity and structure of garlic accessions from Brazil. Genetica 142: 419-431. https://doi.org/10.1007/s10709-014-9786-1

Dice LR (1945). Measures of the amount of ecologic association between species. Ecology 26: 297-302. https://doi. org/10.2307/1932409

Evanno G, Regnaut S and Goudet J (2005). Detecting the number of clusters of individuals using the software STRUCTURE: a simulation study. Mol. Ecol. 14: 2611-2620. https://doi.org/10.1111/j.1365-294X.2005.02553.x

Hamza S, Hamida WB, Rebai A and Harrabi M (2004). SSR-based genetic diversity assessment among Tunisian winter barley and relationship with morphological traits. Euphytica 135: 107-118. https://oi.org/10.1023/ B:EUPH.0000009547.65808.bf

Harlan JR (1975). Our vanishing genetic resources. Science 188: 617-621. https://doi.org/10.1126/science.188.4188.617

Lee JK and Ohnishi O (2001). Geographical differentiation of morphological characters among Perilla crops and their weedy types in East Asia. Breed. Sci. 51: 247-255. https://doi.org/10.1270/jsbbs.51.247

Lee JK and Ohnishi O (2003). Genetic relationships among cultivated types of Perilla frutescens and their weedy types in East Asia revealed by AFLP markers. Genet. Resour. Crop Evol. 50: 65-74. https://doi.org/10.1023/A:1022951002271

Lee JK and Kim NS (2007). Genetic Diversity and Relationships of Cultivated and Weedy types of Perilla frutescens Collected from East Asia revealed by SSR Markers. Yugjong Haghoeji 39: 491-499.

Lee JK, Nitta M, Kim NS, Park CH, et al. (2002). Genetic diversity of Perilla and related weedy types in Korea determined by AFLP analyses. Crop Sci. 42: 2161-2166. https://doi.org/10.2135/cropsci2002.2161

Li HL (1969). The vegetables of ancient China. Econ. Bot. 23: 235-260. https://doi.org/10.1007/BF02860457

Liu C, Fan X, Jiang J, Guo D, et al. (2014). Genetic diversity of Chinese wild grape species by SSR and SRAP markers. Biotechnol. Biotechnol. Equip. 26: 2899-2903. https://doi.org/10.5504/bbeq.2011.0146

Liu K and Muse SV (2005). PowerMarker: an integrated analysis environment for genetic marker analysis. Bioinformatics 21: 2128-2129. https://doi.org/10.1093/bioinformatics/bti282

Makino T, Hara H, Tuyama T and Fumio M (1961). Makino's New Illustrated Flora of Japan. Hokuryukan, Tokyo.

Meng F, Liu L, Peng M, Wang ZK, et al. (2015). Genetic diversity and population structure analysis in wild strawberry (Fragaria nubicola L.) from Motuo in Tibet Plateau based on simple sequence repeats (SSRs). Biochem. Syst. Ecol. 63: 113-118. https://doi.org/10.1016/j.bse.2015.09.018

Nitta M (2001). Origin Perilla crops and their weedy type. Ph.D. thesis, Kyoto University, Kyoto.

Nitta M and Ohnishi O (1999). Genetic relationships among two Perilla crops, shiso and egoma, and the weedy type revealed by RAPD markers. Jpn. J. Genet. 74: 43-48.

Nitta M, Lee JK and Ohnishi O (2003). Asian Perilla crops and their weedy forms: their cultivation, utilization and genetic relationships. Econ. Bot. 57: 245-253. https://doi.org/10.1663/0013-0001(2003)057[0245:APCATW]2.0.CO;2

Park YJ, Dixit A, Ma KH, Lee JK, et al. (2008). Evaluation of genetic diversity and relationships within an on-farm collection of Perilla frutescens (L.) Britt. using microsatellite markers. Genet. Resour. Crop Evol. 55: 523-535. https://doi.org/10.1007/s10722-007-9258-x

Park YJ, Lee JK and Kim NS (2009). Simple sequence repeat polymorphisms (SSRPs) for evaluation of molecular diversity and germplasm classification of minor crops. Molecules 14: 4546-4569. https://doi.org/10.3390/molecules14114546

Park YJ, Ramekar RV, Sa KJ and Lee JK (2015). Genetic diversity, population structure, and association mapping of biomass traits in maize with simple sequence repeat markers. Genes Genomics 37: 725-735. https://doi.org/10.1007/ s13258-015-0309-y

Powell W, Morgante M, Andre C, Hanafey M, et al. (1996). The comparison of RFLP, RAPD, AFLP and SSR (microsatellite) markers for germplasm analysis. Mol. Breed. 2: 225-238. https://doi.org/10.1007/BF00564200

Prasad M, Varshney RK, Roy JK, Balyan HS, et al. (2000). The use of microsatellites for detecting DNA polymorphism, genotype identification and genetic diversity in wheat. Theor. Appl. Genet. 100: 584-592.

Pritchard JK and Wen W (2003). Documentation for STRUCTURE software: Version 2.

Rao NK (2004). Plant genetic resources: Advancing conservation and use through biotechnology. Afr. J. Biotechnol. 3: 136-145.

Rao VR and Hodgkin T (2002). Genetic diversity and conservation and utilization of plant genetic resources. Plant Cell Tissue Organ Cult. 68: 1-19. https://doi.org/10.1023/A:1013359015812

Rohlf FJ (1998). NTSYS-pc: Numerical taxonomy and multivariate analysis system. Version: 2.02. Exter Software, Setauket, New York.

Genetics and Molecular Research 16 (3): gmr16039746 
Sa KJ, Choi SH, Ueno M, Park KC, et al. (2013). Identification of genetic variations of cultivated and weedy types of Perilla species in Korea and Japan using morphological and SSR markers. Genes Genomics 35: 649-659. https://doi. org/10.1007/s13258-013-0117-1

Sa KJ, Choi SH, Ueno M and Lee JK (2015). Genetic diversity and population structure in cultivated and weedy types of Perilla in East Asia and other countries as revealed by SSR markers. Hortic. Environ. Biotechnol. 56: 524-534. https://doi.org/10.1007/s13580-015-0039-8

Senior ML, Murphy JP, Goodman MM and Stuber C (1998). Utility of SSRs for determining genetic similarities and relationships in maize using an agarose gel system. Crop Sci. 38: 1088-1098. https://doi.org/10.2135/cropsci1998.0 011183X003800040034x

Vaiman D, Mercier D, Moazami-Goudarzi K, Eggen A, et al. (1994). A set of 99 cattle microsatellites: characterization, synteny mapping, and polymorphism. Mamm. Genome 5: 288-297. https://doi.org/10.1007/BF00389543

Villa TCC, Maxted N, Scholten M and Ford-Lloyd B (2006). Defining and identifying crop landraces. Plant Genet. Resour. 3: 373-384. https://doi.org/10.1079/PGR200591

Wang R, Yu Y, Zhao J, Shi Y, et al. (2008). Population structure and linkage disequilibrium of a mini core set of maize inbred lines in China. Theor. Appl. Genet. 117: 1141-1153. https://doi.org/10.1007/s00122-008-0852-x

Woo SY, Sa KJ and Lee JK (2016). Collection and Evaluation of Genetic Variation of Perilla Accessions in the Jeju Island. Plant Breed. Biotechnol. 4: 87-98. https://doi.org/10.9787/PBB.2016.4.1.087

Xia XC, Reif JC, Melchinger AE, Frisch M, et al. (2005). Genetic diversity among CIMMYT maize inbred lines investigated with SSR markers: II. Subtropical, tropical midaltitude, and highland maize inbred lines and their relationships with elite U.S. and European maize. Crop Sci. 45: 2573-2582. https://doi.org/10.2135/cropsci2005.0246

Xie W, Zhang X, Cai H, Liu W, et al. (2010). Genetic diversity analysis and transferability of cereal EST-SSR markers to orchardgrass (Dactylis glomerata L.). Biochem. Syst. Ecol. 38: 740-749. https://doi.org/10.1016/j.bse.2010.06.009

Yook MJ, Lim SH, Song JS, Kim JW, et al. (2014). Assessment of genetic diversity of Korean Miscanthus using morphological traits and SSR markers. Biomass Bioenergy 66: 81-92. https://doi.org/10.1016/j.biombioe.2014.01.025

Zeven AC (1998). Landraces: a review of definitions and classifications. Euphytica 104: 127-139. https://doi. org/10.1023/A:1018683119237

Genetics and Molecular Research 16 (3): gmr16039746 